\title{
Avaliação psicológica e prognóstico de comportamento desviante numa corporação militar
}

\author{
Divino Pereira de Brito ${ }^{1}$ \\ Iris B. Goulart ${ }^{2}$
}

\begin{abstract}
Resumo
Este trabalho é um relatório de pesquisa documental realizada numa corporação policial militar, na qual o exame psicológico é utilizado no processo seletivo. Pela análise dos registros da referida corporação, foram identificados os casos de desvio de comportamento praticados por policiais contra-indicados ou indicados com restrições com base no exame psicológico e admitidos por ordem judicial ou por falta de contingente no período compreendido entre 1994 e 2002. Foram confrontados os desvios cometidos com o resultado do exame psicológico realizado por ocasião do processo seletivo e contatou-se que entre os policiais militares de conduta desviante há uma significativa incidência de contra-indicados no exame psicológico, que foram admitidos. A pesquisa oferece ao comando da corporação e ao Ministério Público argumentos reforçadores da utilização do exame psicológico como recurso destinado ao prognóstico de comportamento desviante.
\end{abstract}

Palavras-Chave: Avaliação psicológica; Carreira policial; Comportamento desviante.

\section{Psychological evaluation and prognosis of deviant behaviour in a military corporation}

\begin{abstract}
The present work is a report of a documental research which was carried out in a military corporation, where a psychological examination is used as part of the selection of the admission process. Based upon the analysis of records of the aforementioned corporation, the research identified the cases of deviant behaviour of police officers who were contraindicated or indicated with restrictions for the police work, according to the results of the psychological examinations, being admitted into the police force by means of judicial order or lack of contingent in the period between 1994 e 2002. Such deviations of behaviour were confronted with the result of the psychological examination which was carried out then and it was observed that, among military police officers whose behaviour was deviant, there is a significant incidence of contraindicated people in the psychological examination who happened to be admitted into the police force. The research offers the local police authority and the Department of Justice arguments strengthening the use of the psychological examination as a means of providing prognosis of the deviant behaviour.
\end{abstract}

Keywords: Psychological evaluation; Police career; Deviant behaviour.

\section{Introdução}

A Segurança Pública é um dos problemas mais preocupantes com os quais a sociedade convive no início do século XXI. No Brasil, onde as desigualdades sociais vêm contribuindo para o aumento da criminalidade e violência, a expectativa da população em relação aos responsáveis por esta segurança é ainda maior e, por isto, espera-se que os policiais tenham um comportamento ético capaz de assegurar a confiança da população. Assim, o comportamento desviante de um policial militar, além de denegrir a imagem da organização perante a opinião pública, pode gerar prejuízo financeiro e moral ao Estado e à sociedade, em decorrência dos seus efeitos danosos.

Avaliação psicológica é a designação utilizada neste trabalho para o julgamento que se faz sobre as características psicológicas de um indivíduo ou de um grupo de indivíduos, com base em informações colhidas mediante a utilização de instrumentos construídos com base na ciência psicológica. Destacam-se entre esses instrumentos os testes psicológicos, os questionários, as entrevistas, as técnicas projetivas, as observações situacionais, as técnicas de dinâmica de grupo.

A utilização de instrumentos de avaliação psicológica, especialmente testes, teve início nas organizações militares, especialmente nas Forças Armadas americanas, provavelmente desde a Primeira até a Segunda Guerra

Endereço para correspondência:

${ }^{1}$ Estado Maior da Polícia Militar - Praça da Liberdade, Belo Horizonte-MG

${ }^{2}$ FEAD-Minas - Centro de Gestão Empreendedora

Rua Américo Macedo, 232-30430-190 - Belo Horizonte-MG

E-mail: irisgoulart@terra.com.br e iris.goulart@fead.br 
Mundial. Nos anos que se seguiram o final da guerra, houve uma apropriação dos instrumentos pelas diversas organizações, visando "colocar o homem certo no lugar certo" (Anastasi \& Urbina, 2000, p. 19).

Balestreri (2003, p. 34), ao abordar os critérios de seleção, permanência e acompanhamento psicológico de policiais, afirma que há uma preferência natural das pessoas para ingressarem nas profissões nas quais se faz uso da autoridade, citando como exemplo as Forças Armadas e a Polícia, afirmando:

\section{Profissões magnificas, de grande amplitude social, que agre- gam heróis e mesmo santos, são as mesmas que atraem a escória, pelo alcance que têm, pelo poder que representam. A permissão para o uso da força, das armas, do direito a decidir sobre a vida e a morte exerce irresistivel atração à perversidade, ao delírio onipotente, à loucura articulada. Os processos de seleção de policiais devem tornar-se cada vez. mais rígidos no bloqueio à entrada desse tipo de gente. Igualmente, é nefasta a falta de um maior acompanba- mento psicológico aos policiais já na ativa.}

$\mathrm{Na}$ corporação militar que neste trabalho será designada como Corporação YZ, o processo seletivo dos candidatos inclui a avaliação psicológica. No início do ano de 1963, passou-se a utilizar testes psicológicos apenas na seleção de candidatos ao Curso de Formação de Oficiais. Até o ano de 1975, o processo seletivo para inclusão de soldados não incluía a avaliação psicológica e muitos candidatos eram, inclusive, analfabetos ou semi-analfabetos. De 1975 até os dias atuais, quando foi criado na corporação o Quadro de Oficiais Psicólogos, a avaliação psicológica passou a ser efetivamente realizada de forma objetiva e padronizada.

Atualmente, a avaliação psicológica, que constitui uma das etapas do processo seletivo, inclui o uso de um conjunto de instrumentos destinados a analisar as áreas cognitiva e de personalidade dos candidatos, de modo a verificar se esses apresentam o perfil profissiográfico estabelecido para o cargo pretendido. A realização desta avaliação envolve, além dos 53 psicólogos do quadro da corporação, outros que são contratados para realizar o processo seletivo. $\mathrm{Na}$ oportunidade, são utilizados os seguintes instrumentos: uma bateria de testes de aptidão, testes projetivos e expressivos e outras técnicas, definidas com base na análise do perfil profissiográfico e dos fatores de contra-indicação para o cargo. Uma vez submetidos ao processo seletivo, são eliminados do certame os candidatos contra-indicados na avaliação, ou seja, aqueles que demonstram não possuir os traços de personalidade e as habilidades compatíveis com o perfil profissiográfico estabelecido.

A partir dos anos 1990, quando a crise de desemprego se agravou, passou a haver um incremento da procura pelos concursos públicos e muitos candidatos reprovados no processo seletivo em razão de seus resultados na avaliação psicológica têm recorrido à Justiça. $\mathrm{O}$ argumento de seus advogados é de que há ilegalidade, cerceamento do direito ao contraditório, falta de objetividade e transparência no processo seletivo. Estes recursos ensejam inúmeras decisões judiciais de primeira instância favoráveis aos contra-indicados, que vêm sendo admitidos por meio de concessão de liminares. Por outro lado, a ampliação dos quadros da corporação levou ao "aproveitamento" dos candidatos contra-indicados em decorrência da falta de contingente para o preenchimento das vagas disponíveis.

Diante dessa nova realidade, a Corporação YZ tem buscado definir o perfil profissiográfico desejado para os cargos de soldado e oficial, passando a considerar, no processo seletivo, aqueles traços que se manifestam contrários ao perfil estabelecido para o cargo pretendido, ou seja, o candidato é avaliado no seu contraperfil. Desse modo, por ocasião dos concursos, o perfil profissiográfico para cada cargo é divulgado por edital, ao mesmo tempo em que são esclarecidas as condições de realização das avaliações.

Entre as competências específicas do perfil do policial militar inclui-se a capacidade de exercício da liderança sob forte pressão externa e interna, controle emocional para o porte de arma de fogo, além de se realçar a possibilidade de risco de vida, de invalidez, contágio por doenças, degeneração do estado de saúde mental e lesão corporal.

Esta pesquisa partiu do pressuposto de que os servidores contra-indicados ou indicados com restrição são mais suscetíveis de sofrerem as influências do ambiente violento no qual são inseridos em razão de sua profissão e, conseqüentemente, mais propensos a apresentar desvios de comportamento. Para analisar esse pressuposto, a pesquisa buscou analisar a correlação entre os resultados de exames psicológicos dos candidatos contra-indicados ou indicados com restrição e os desvios de comportamento praticados por eles. Para isto, foram definidos objetivos secundários, tais como: organizar dados disponíveis, porém dispersos, sobre resultados de exames psicológicos; identificar os casos de demissão e os de suicídio e crimes cometidos por militares, estabelecendose uma correlação com os resultados dos exames. Deste modo, foram levantados, nos arquivos da corporação, os resultados dos testes psicológicos aplicados aos policiais militares que ingressaram na organização a partir de 1o de janeiro de 1994 até 31 de dezembro de 2002, bem como a listagem dos desvios de comportamento praticados por esses policiais. Procedeu-se, em seguida, a uma análise comparativa entre os "Indicados" e os "Contra-Indicados", verificando-se, a partir daí, em qual dos dois grupos era maior a incidência de desvios de comportamento.

Psico-USF, v. 10, n. 2, p. 149-160, jul./ dez. 2005 
Por ocasião da admissão de tais policiais, havia uma expectativa de que os mesmos viessem a ser devidamente acompanhados. Entretanto, só a partir de 1999 os procedimentos de acompanhamento psicoterapêutico vêm sendo adotados e, mesmo assim, apenas durante o período de formação, já que uma uma vez formados, os policiais militares são distribuídos nas diversas unidades e o acompanhamento se encerra.

O policial militar é regido por dois conjuntos de normas distintas, ou seja, como cidadão comum, ele está sujeito às leis que regem a sociedade como um todo e, como militar, tem deveres e obrigações inerentes a essa condição, cujo regime lhe impõe um código de ética, um código penal próprio e rígido, que é o Código Penal Militar, além de muitas normas internas que devem ser cumpridas rigorosamente.

A exposição pública de seus atos e a ostensividade decorrente do uso da farda, bem como a postura exigida pelos regulamentos e pela sociedade, que sempre espera um comportamento exemplar dos profissionais de segurança pública, criam nesse policial um estado de tensão permanente, que após alguns anos pode determinar adoecimento físico (úlceras, diabetes, cefaléia constante) e psíquico (ansiedade, paranóia, síndrome de pânico, entre outras manifestações).

Este cotidiano tenso, no qual o policial militar é exposto a pressões internas e externas, explica a emergência de diversos casos de desvio de comportamento, incluindo os registros de suicídio - tanto daqueles que estão no serviço ativo como dos que já passaram para a inatividade. Daí, a necessidade de se garantir que a entrada na carreira policial militar seja permitida apenas àqueles que evidenciem significativo controle emocional.

Numa abordagem psicossocial, considera-se o comportamento desviante como uma fuga às expectativas normativas predominantes. Assim, determinadas pessoas resistem ao cumprimento das normas impostas e aceitas pelo grupo social, passando a se comportar como se não estivessem sujeitas a elas. Esta ausência de normas, que é denominada anomia, tem sido estudada por diversos autores, entre os quais deve ser lembrado Robert K. Merton (1968), que considera a desorganização social a principal causa do comportamento desviante. Esse autor enfatiza que a sociedade, em suas diversas classes, estabelece as metas e os meios legítimos para alcançá-las; o comportamento desviante ocorre exatamente quando o indivíduo, não dispondo dos meios legítimos para alcançar suas metas, lança mão dos meios ilegítimos para atingir os fins pretendidos.

Antes da pesquisa que é relatada neste artigo, outras já foram realizadas sobre o comportamento desviante dos policiais militares, entre as quais destacamos algumas.

Patrocínio (1997) realizou pesquisa na mesma Corporação YZ, utilizando a caracterização da CID - 10 Psico-USF, v. 10, n. 2, p. 149-160, jul./ dez. 2005
(Classificação Internacional de Doenças) para identificar a conduta anti-social, que é caracterizada por: a) indiferença insensível pelos sentimentos alheios: b) atitude flagrante e persistente de irresponsabilidade e desrespeito por normas, regras e obrigações sociais; c) incapacidade de manter relacionamentos, embora não haja dificuldade em estabelecê-los; d) muito baixa tolerância à frustração e um baixo limiar para descarga de agressão, incluindo violência; e) incapacidade de experimentar culpa e de aprender com a experiência, particularmente punição; f) propensão marcante para culpar os outros ou para oferecer racionalizações plausíveis para o comportamento que levou o paciente a conflito com a sociedade (Patrocínio, 1997, p. 69).

Nicolau (1993), em pesquisa realizada na corporação ora estudada, analisou vários fatores que contribuem para a ocorrência de desvios de conduta, e apontou para a necessidade de se proceder a uma revisão das políticas de recursos humanos, especialmente no que diz respeito aos procedimentos usados no processo seletivo, sugerindo a melhoria do processo de formação e acompanhamento dos policiais.

Freitas (1995) desenvolveu uma pesquisa sobre a conduta de policiais militares que prejudicam a imagem institucional e que chocam a opinião pública, apresentando como sugestões a serem adotadas pela organização: o real acompanhamento dos policiais militares que, no exame psicotécnico, são indicados com restrição e com acompanhamento; e o exame detalhado da vida e carreira do policial militar que cometeu faltas diferentes daquelas constantes da disciplina militar (Freitas, 1995, p. 99).

Esta pesquisa tomou como referência os desvios de comportamento listados pela corporação estudada, que são os seguintes: as transgressões disciplinares, a prática de crimes diversos e, especificamente, o suicídio.

- Transgressão disciplinar - é a inobservância ou violação do dever policial militar, previsto no Código de Ética e Disciplina Militares, que entrou em vigor a partir do dia 4 de agosto de 2002. Este novo Código de Ética e Disciplina Militares é considerado um código moderno, mais humano e democrático que o anterior, concebido e ajustado para garantir, com melhor clareza, o direito ao contraditório e à ampla defesa e a maior liberdade de expressão do policial, sendo menos rigoroso no que se refere ao comportamento militar, e mais voltado para a conduta policial do servidor.

De acordo com os registros disponíveis no sistema informatizado da Diretoria de Recursos Humanos da Corporação YZ, as dez principais transgressões disciplinares são as seguintes, em ordem decrescente de ocorrência: trabalhar mal em qualquer 
serviço ou instrução; faltar ao serviço; deixar de cumprir normas regulamentares; chegar atrasado para o serviço; afastar-se do local de serviço; ter postura inconveniente, falta de compostura, inobservância aos princípios da boa educação e moral; negligenciar o cumprimento de ordem; ter conduta incompatível com os princípios e valores policiais militares; contrariar regras de trânsito; dormir em serviço.

- Prática de crimes diversos (crime comum e crime militar) A prática de crimes por parte de policiais militares tem sido o desvio de comportamento que mais chama a atenção da opinião pública, sobretudo pelo impacto negativo que causa na população. Os registros existentes na 2a seção do Estado Maior da corporação $\mathrm{YZ}$ enumeram os crimes praticados por policiais militares, em ordem decrescente de ocorrência: embriaguez em serviço; violência arbitrária; homicídio doloso consumado; corrupção passiva; estelionato; uso de placa "fria" ou "clonada"; furto qualificado ou apropriação indébita; roubo a mão armada consumado (assalto); tortura.

\section{- O suicídio}

É importante considerar que nas organizações militares estaduais brasileiras o número de registros de suicídio tende a se apresentar em patamares superiores à média geral da população. Na corporação $\mathrm{YZ}$, alguns estudos estão em andamento e outros já foram concluídos. Resende e Cavazza (1999, p. 54), em um estudo sobre os aspectos da violência policial, trazem o seguinte comentário:

\section{A incidência de suicídio em instituicōes militares é significativamente mais elevada em relação à população em geral. Segundo a Revista Veja (agosto/99), a taxa de suicidio entre os PMs do Brasil é sete vezes maior do que entre os não-policiais.}

Nogueira e Moreira (1997) realizaram um estudo sobre o auto-extermínio entre policiais militares na mesma corporação abordada nesta pesquisa, e observam que a idealização do policial militar como um super-herói, um ser perfeito, sem faltas, pode contribuir para gerar conflitos intra e interpessoais, que culminam no suicídio.

\section{Método}

O ponto de partida para esta pesquisa foi o indicativo de que vários atos anti-sociais praticados por integrantes da Corporação YZ têm como envolvidos diretos os servidores que foram contra-indicados no exame psicológico. Alguns deles foram demitidos por responsabilidade disciplinar ou por envolvimento em crimes diversos, enquanto outros não foram demitidos mas foram indiciados em inquérito policial. Há ainda os que cometeram suicídio, os quais também são sujeitos incluídos neste estudo.

Foi realizada uma pesquisa documental, já que se recorreu aos arquivos da instituição estudada para recolher os dados referentes aos policiais militares admitidos de 1994 a 2000. Foram confrontados os resultados da avaliação psicológica com os registros de comportamentos desviantes, o que deu à pesquisa um caráter correlacional.

Quanto à natureza, a pesquisa é quantitativa. Inicialmente, foram feitas entrevistas com os psicólogos da organização, a fim de se obter informações relativas ao processo seletivo e especialmente à avaliação psicológica adotada: quais os instrumentos utilizados, quem era responsável pela aplicação dos testes e interpretação dos resultados. A interpretação dessas entrevistas forneceu elementos para se apresentar o processo seletivo. Os dados referentes aos registros funcionais (prontuários) dos militares e ex-militares, os resultados dos exames psicológicos e os registros de desvios de comportamento foram coletados nos arquivos da Corporação YZ. Posteriormente, esses dados foram confrontados e submetidos a tratamento estatístico, caracterizando uma abordagem quantitativa.

Foi uma pesquisa censitária, sendo seu universo composto de:

a) 10.543 policiais militares que ingressaram na Corporação YZ entre 1994 e 2002 e que estão no serviço ativo;

b) os policiais militares que ingressaram na Corporação YZ entre 1994 e 2002 e que foram demitidos entre 2000 e 2002 e os que, tendo ingressado no mesmo período, cometeram crimes mas não foram demitidos;

c) os policiais militares admitidos entre $1994 \mathrm{e}$ 2002 e que cometeram suicídio nesse período.

A hipótese principal que delimitou a pesquisa foi a seguinte:

Os integrantes da Corporação YZ admitidos entre os anos de 1994 e 2002, na condição de Soldados e Sargentos que, com base no exame psicológico, foram contra-indicados ou indicados com restrição são mais propensos a cometer desvio de comportamento do que aqueles que são aprovados sem restriçōes no referido exame.

As hipóteses secundárias formuladas pelos pesquisadores foram as seguintes:

Primeira - Um numero significativo de policiais militares que cometeram suicídio foi contra-indicado ou indicado com restrição no exame psicológico.

Segunda - Os policiais militares contra-indicados no exame psicológico têm se envolvido na prática de crimes e transgressões diversas mais do que os indicados.

Psico-USF, v. 10, n. 2, p. 149-160, jul./dez. 2005 
O primeiro passo da pesquisa foi a obtenção de uma relação atualizada de todos os policiais militares da ativa que ingressaram na Corporação YZ a partir do ano de 1994, fornecida pela Companhia de Processamento de Dados do Estado. De posse desta relação, foram excluídos da pesquisa:

1) os policiais militares que exercem atividades burocráticas e os do quadro de saúde, uma vez que têm pouco contato com o público externo, não trabalham no policiamento ostensivo e não participam de operações. Esses policiais raramente vivenciam situações de conflito e tensão e não atendem a ocorrências, sendo reduzidas as chances de, no exercício da atividade, ficarem expostos às condições ambientais que podem influenciar ou ensejar desvio de comportamento;

2o) os cadetes e alunos dos Cursos de Formação de oficiais, assim como os próprios oficiais, que não são expostos às mesmas condições de trabalho dos cabos, soldados e sargentos.

Em seguida, buscou-se, na Seção do Estado Maior, a relação nominal dos policiais militares que cometeram crimes no período de 2000 a 2002, verificando-se, individualmente, o tipo de desvio e a unidade a que pertencem.

$\mathrm{Na}$ Diretoria de Recursos Humanos (DRH), foi obtida a relação nominal dos ex-policiais militares que ingressaram na corporação a partir do ano de 1994, por unidade, averiguando-se, dentre estes, os que foram demitidos no período de 2000 a 2002, com a indicação dos motivos que levaram à demissão. Obteve-se também, nesta Diretoria, a relação de todos os ex-servidores que ingressaram na Corporação YZ a partir de 1994 e que cometeram suicídio.

Após a análise de cada conjunto de dados, foram elaboradas as respectivas relações desses três grupos distintos, a fim de facilitar a comparação dos nomes com os resultados do exame psicológico, por meio das atas fornecidas pelo Serviço de Recrutamento e Seleção. Em seguida, procedeu-se ao levantamento dos resultados dos testes psicológicos dos servidores e exservidores em cada grupo, separadamente, elaborandose uma planilha contendo estes dados.

No decorrer dos trabalhos as dificuldades abaixo trouxeram limitações à pesquisa:

- a impossibilidade de se localizar, nos arquivos, todas as listagens (atas) contendo as relações nominais e os resultados dos exames psicológicos dos policiais militares (candidatos) que participaram do processo seletivo, principalmente em relação aos concursos de 1994 e 1995, em face do tempo já decorrido;

- a dispersão dos policiais militares após a formatura e a impossibilidade de se localizarem os nomes dos que foram transferidos de suas respectivas unidades de origem;

- a impossibilidade de se verificar, integralmente, os resultados dos testes psicológicos dos policiais militares pertencentes aos batalhões que foram criados mais recentemente, cujos servidores são oriundos de várias outras unidades;

- a perda de elementos do universo analisado. De um total de 10.543 servidores, foi possível verificar 7.084 nomes, o que corresponde a $67,19 \%$ do total, havendo, portanto, uma perda de $32,81 \%$, ou seja, 3.459 sobre os quais não foi possível efetuar a análise dos resultados.

\section{Análise e interpretação dos resultados}

Do total de servidores admitidos na Corporação YZ no período compreendido entre 1994 e 2002, no período de 2000 a 2002 houve as perdas apresentadas na Tabela 1 .

Tabela 1 - Policiais militares admitidos na Corporação YZ entre 1994 e 2002 e excluídos entre 2000-2002

\begin{tabular}{lc}
\hline Motivo da exclusão & Quantidade \\
\hline Exclusão disciplinar & 64 \\
Falecimento em acidente fora do serviço & 17 \\
Assassinados fora do serviço & 11 \\
Morte natural & 9 \\
Assassinados em serviço & 8 \\
Falecimento em acidente no serviço & 5 \\
Suicídio & 5 \\
Soma & 119 \\
\hline
\end{tabular}

Fonte: Diretoria de Recursos Humanos da Corporação YZ.

No período de 1994 a 2002, a Corporação YZ admitiu um total de 11.973 servidores nos quadros de Soldado, Cabo Especialista, Sargento, Cadete e Oficial. Excluindo-se desse total os cadetes, os oficiais, que não Psico-USF, v. 10, n. 2, p. 149-160, jul./dez. 2005 foram objeto deste estudo, e considerando apenas os policiais militares que estão na ativa, constitui o universo desta pesquisa um total de 10.543 policiais militares, os quais foram admitidos na condição de 
Soldado e Sargento. A exclusão de oficiais e cadetes se justifica porque as condições de trabalho desses profissionais diferencia-se da que é própria dos policiais que trabalham no policiamento ostensivo.

Em face das dificuldades e limitações já enumeradas, houve uma perda de $32,81 \%$ deste total, ou seja, 3.459 policiais. A amostra desta pesquisa foi, portanto, consti- tuída de 7.084 policiais, cujos nomes foram alinhados com o resultado do exame psicológico. Verificou-se que 1.901 foram contra-indicados, o que corresponde a 26,83\% desse total. Esses resultados estão apresentados na Tabela 2, ressaltando que não estão incluídos neste universo os policiais militares que já foram demitidos e os que se suicidaram, os quais fazem parte de um outro grupo de avaliação.

Tabela 2 - Resultado do exame psicológico dos policiais militares admitidos entre 1994 e 2002

\begin{tabular}{lcc}
\hline \multirow{2}{*}{ Resultado do exame psicológico } & & Freqüência \\
\cline { 2 - 3 } & Absoluta & Percentual $(\%)$ \\
\hline Indicados & 3.073 & 29,15 \\
Indicados com restrição & 2.107 & 19,99 \\
Contra-indicados & 1.901 & 18,03 \\
Eliminados & 3 & 0,02 \\
Não apurados & 3.459 & 32,81 \\
Total & 10.543 & 100 \\
\hline
\end{tabular}

Fonte: Dados da pesquisa.

Essa tabela permite inferir que os eliminados no exame psicológico correspondem a menos de $1 \%$ do total de candidatos, o que representa um valor pouco significativo em relação ao total de concorrentes. Mesmo assim, esses candidatos acabaram sendo admitidos por necessidade de contingente ou por mandado judicial.
Com base na análise da Tabela 3, verifica-se que, no período coberto pela pesquisa, os anos de 1994 e 1995 foram aqueles em que a Corporação YZ admitiu o maior número de candidatos contra-indicados pelo exame psicológico.

Tabela 3 - Policiais militares contra-indicados no exame psicológico, admitidos entre 1994 e 2002

\begin{tabular}{cc}
\hline Ano & Freqüência \\
\hline 1994 & 631 \\
1995 & 691 \\
1996 & 168 \\
1997 & 2 \\
1998 & 11 \\
1999 & 26 \\
2000 & - \\
2001 & - \\
2002 & 372 \\
Total & 1.901 \\
\hline
\end{tabular}

Fonte: Dados da pesquisa.

Obs: (-) Sinal correspondente a zero registro.

A partir do ano de 1997, a Corporação YZ passou a admitir candidatos contra-indicados no exame psicológico somente mediante determinação judicial, o que nos permite verificar, pela tabela apresentada, que no ano de 2002 um número expressivo de liminares concedidas pelo Poder Judiciário determinou a inclusão de candidatos contra-indicados.
No período de 1o de janeiro de 2000 a 31 de dezembro de 2002, a Corporação YZ aplicou um total de 23.514 punições por atos contrários ao Regulamento Disciplinar e ao Código de Ética e Disciplina dos Servidores Militares Estaduais, conforme consta da Tabela 4, a seguir: 
Tabela 4 - Transgressões disciplinares e respectivas sanções administrativas aplicadas na Corporação YZ - 2000-2002

\begin{tabular}{clcccc}
\hline Item/ & \multicolumn{1}{c}{ Transgressão } & \multicolumn{3}{c}{ Quantidade/Ano } \\
\cline { 3 - 5 } RDPM & & 2000 & 2001 & 2002 & Total \\
\hline 021 & Trabalhar mal em qualquer serviço/instrução & 1.410 & 1.040 & 724 & 3.174 \\
024 & Faltar ao serviço & 1.298 & 1.075 & 677 & 3.050 \\
007 & Deixar de cumprir normas regulamentares & 907 & 1.056 & 643 & 2.606 \\
023 & Chegar atrasado para o serviço & 657 & 540 & 374 & 1.571 \\
027 & Afastar-se do local de serviço & 601 & 475 & 301 & 1.377 \\
101 & Postura inconveniente, falta de compostura, & 450 & 336 & 278 & 1.064 \\
& inobservância de princípios de educação e moral & & & & \\
018 & Negligenciar o cumprimento de ordem & 371 & 341 & 203 & 915 \\
163 & Ter conduta incompatível com os princípios e & 339 & 305 & 240 & 884 \\
& valores policiais militares & & & & \\
080 & Contrariar regras de trânsito & 242 & 185 & 150 & 577 \\
146 & Dormir em serviço & 226 & 153 & 98 & 477 \\
& Outras & 3.030 & 2.217 & $2.572^{*}$ & 6.785 \\
Total & & 9.531 & 7.723 & 6.260 & 23.514 \\
\hline
\end{tabular}

Fonte: Diretoria de Recursos Humanos da Corporação YZ.

Obs.: (*) Estão incluídas as punições relativas ao Código de Ética e Disciplina dos Militares Estaduais, no total de 1.034, as quais foram aplicadas no período de 4.8.02 a 31.12.02.

$\mathrm{Na}$ análise das transgressões disciplinares foram considerados apenas os casos já apurados e que resultaram em punição aos transgressores, cujas infrações são aquelas previstas no RDPM (Regulamento Disciplinar da Polícia Militar) e no Código de Ética, ressaltando que o RDPM ficou em vigor até o dia 3.8.2002, quando foi revogado, e, no dia 4.8.2002, a Organização passou a adotar o Código de Ética e Disciplina dos Militares Estaduais, que trouxe uma nova classificação e tipificação para as transgressões disciplinares. Pode-se observar, também, que a partir 2002, quando foi implantado o novo Código, que é menos rigoroso, registrou-se uma redução significativa na quantidade de punições aplicadas.

Do contingente de servidores admitidos entre 1994 e 2002, procedeu-se ao levantamento de quantos foram demitidos entre 2000 e 2002 e os respectivos resultados do exame psicológico desses ex-policiais, conforme demonstrado na Tabela 5.

Tabela 5 - Policiais militares contra-indicados no exame psicológico, admitidos entre 1994 e 2002 e demitidos entre 2000 e 2002

\begin{tabular}{lc}
\hline Resultado do exame psicológico & Quantidade \\
\hline Indicado & 14 \\
Indicado com restrição & 21 \\
Contra-indicado & 26 \\
Eliminado & 3 \\
Total & 64 \\
\hline
\end{tabular}

Fonte: Diretoria de Recursos Humanos e Centro de Recrutamento e Seleção.

Pode-se observar que, do total de servidores demitidos no período considerado, houve uma predominância de contra-indicados no exame psicológico, o que vem comprovar a hipótese principal da pesquisa, de que os policiais militares contra-indicados no exame psicológico por ocasião do processo seletivo têm maior probabilidade de cometer desvios de comportamento do que os candidatos indicados sem restrições.

A sustentação para esta afirmativa é o fato de que, dos 1.901 servidores contra-indicados no exame psicológico, comparando-os com os 3.084 indicados, há uma relação de 6,2 contra-indicados para cada grupo de 10 indicados, enquanto entre os demitidos, para cada grupo de 10 indicados há 18,5 contraindicados.

Pela Tabela 6, verifica-se a situação dos policiais militares demitidos, por graduação, havendo uma predominância de soldados de $1 \underline{a}$ classe nesse grupo. 
Tabela 6 - Policiais militares admitidos entre 1994 e 2002 e demitidos entre 2000 e 2002, por graduação

\begin{tabular}{lc}
\hline Graduação & Quantidade \\
\hline 3o sargento & 2 \\
Cabo & 11 \\
Soldado de 1a classe & 47 \\
Soldado de 2a classe & 4 \\
Total & 64 \\
\hline
\end{tabular}

Fonte: Diretoria de Recursos Humanos e Centro de Recrutamento e Seleção.

Obs.: Soldado de $1 \underline{a}$ classe é aquele que já concluiu o curso de formação.

Observa-se que, do total de servidores demitidos, 4 eram soldados de 2 a classe (alunos em curso de formação), os quais não completaram nem um ano de serviço na Organização, o que é preocupante, pois demonstra uma inadaptação desses ex-servidores à carreira policial militar, uma questão que merece ser melhor avaliada pelos psicólogos.
A Tabela 7 apresenta o resultado do exame psicológico dos candidatos selecionados no período estudado, permitindo identificar a graduação dos mesmos. É possível verificar que, à exceção da categoria soldado de segunda classe, em todas as demais categorias há predominância de policiais contra-indicados e indicados com restrição entre os demitidos.

Tabela 7 - Resultado do exame psicológico dos policiais militares admitidos entre 1994 e 2002 e demitidos entre 2000 e 2002, por graduação

\begin{tabular}{lccccc}
\hline \multirow{2}{*}{ Resultado do exame psicológico } & \multicolumn{5}{c}{ Graduação } \\
\cline { 2 - 6 } & 3o SGT & Cabo & SD 1a Classe & SD 2a Classe & Soma \\
\hline Indicado & - & 1 & 10 & 3 & 14 \\
Indicado c/ restrição & - & 4 & 17 & - & 21 \\
Contra-Indicado & 2 & 5 & 19 & - & 26 \\
Não apurados & - & 1 & 1 & 1 & 3 \\
Total & 2 & 11 & 47 & 4 & 64 \\
\hline
\end{tabular}

Fonte: Diretoria de Recursos Humanos e Centro de Recrutamento e Seleção.

Obs.: (-) Sinal correspondente a zero registro.

A Tabela 8 apresenta os desvios de comportamento que levaram à demissão dos servidores, observando- se que as demissões ocorreram muito mais pelo cometimento de crimes do que por transgressões disciplinares.

Tabela 8 - Desvios de comportamento que motivaram as demissões dos policiais militares admitidos entre 1994 e 2002 e demitidos entre 2000 e 2002

\begin{tabular}{lc}
\hline Desvio de comportamento & Freqüência \\
\hline Mau comportamento & 18 \\
Corrupção & 9 \\
Outros & 6 \\
Tráfico e uso de drogas & 5 \\
Assalto, roubo e latrocínio & 5 \\
Apropriação indébita & 5 \\
Estelionato & 4 \\
Homicídio e tentativa de homicídio & 4 \\
Crimes sexuais & 4 \\
Violência arbitrária & 2 \\
Embriaguez & 2 \\
Total & 64 \\
\hline
\end{tabular}

Fonte: Diretoria de Recursos Humanos e Centro de Recrutamento e Seleção.

Nota-se que há uma diversidade de delitos cometidos pelos policiais militares, com ênfase para os crimes contra o patrimônio e contra a Administração
Pública (assalto, apropriação indébita e corrupção), todos eles incompatíveis com a profissão e, por este motivo, causando maior indignação na sociedade. 
Pela Tabela 9, verifica-se que houve maior incidência dos contra-indicados entre os servidores que cometeram crimes, em comparação com os indicados e indicados com restrição. Pode-se verificar, ainda, que o somatório das categorias contra-indicados e indicados com restrição é 42 , número equivalente à maioria, no caso do total de 72 elementos que praticaram crimes no período.

Tabela 9 - Resultado do exame psicológico dos policiais militares admitidos entre 1994 e 2002 e que cometeram crimes entre 2000 e 2002

\begin{tabular}{lc}
\hline Resultado do exame psicológico & Freqüência \\
\hline Contra-indicado & 28 \\
Indicado & 16 \\
Indicado com restrição & 14 \\
Não apurados & 14 \\
Total & 72 \\
\hline
\end{tabular}

Fonte: Diretoria de Recursos Humanos e Centro de Recrutamento e Seleção.

Estes números vêm comprovar a 2a hipótese da pesquisa, a qual estabelece que os policiais militares contra-indicados no exame psicológico têm se envolvido na prática de crimes e transgressões diversas.

A Tabela 10 mostra os tipos de crimes (desvios de comportamento) cometidos pelos policiais militares, com ênfase para as questões da violência arbitrária, da embriaguez e do homicídio, que prevaleceram sobre os demais. Ressalte-se que os crimes de tortura, violência arbitrária, embriaguez e corrupção foram cometidos no exercício da atividade policial, enquanto os crimes de homicídio, assalto, estelionato, furto qualificado e simples e uso de placa fria foram cometidos fora do serviço.

Tabela 10 - Tipos de crimes cometidos entre 2000 e 2002, pelos policiais militares admitidos entre 1994 e 2002

\begin{tabular}{lc}
\hline Tipo de crime & Freqüência \\
\hline Violência arbitrária & 13 \\
Embriaguez & 12 \\
Homicídio doloso & 11 \\
Furto simples e qualificado & 7 \\
Corrupção passiva & 6 \\
Uso de drogas & 5 \\
Roubo à mão armada (assalto) & 4 \\
Estelionato & 4 \\
Tortura & 3 \\
Uso de placa "fria" & 3 \\
Estupro & 2 \\
Outros & 2 \\
Total & 72 \\
\hline Fo: Esal
\end{tabular}

Fonte: Estado Maior da Corporação YZ.

Em relação ao suicídio, que constitui um problema preocupante nas organizações policiais militares por sua elevada incidência, a pesquisa abrange todos os casos registrados entre 1994 e 2002, cujas vítimas foram os militares admitidos nesse período. Entre os integrantes da Corporação YZ, admitidos no período abordado nesta pesquisa (de 1994 a 2002), houve um total de 25 casos de suicídio, conforme consta da Tabela 11.

Tabela 11 - Policiais militares admitidos entre 1994 e 2002 e que cometeram suicídio no mesmo período

\begin{tabular}{lc}
\hline Graduação & Freqüência \\
\hline 3o sargento & 2 \\
Cabo & 1 \\
Soldado de 1a classe & 19 \\
Soldado de 2a classe & 3 \\
Total & 25 \\
\hline
\end{tabular}

Fonte: Diretoria de Recursos Humanos e Estado Maior.

Psico-USF, v. 10, n. 2, p. 149-160, jul./dez. 2005 
A Tabela 12 nos mostra os resultados do exame psicológico dos ex-policiais militares que cometeram suicídio. É relevante observar que, do total de suicídios, houve uma incidência considerável de soldados de 1a classe. É interessante observar também que os 3 soldados de 2 a classe (recrutas) que cometeram suicídio nem chegaram a concluir o curso de formação, situação esta que deve ser motivo de preocupação para a organização. Ressalte-se ainda que, do total de vítimas, 2 (duas) foram policiais femininos, ressaltando-se que a admissão de mulheres constitui uma peculiaridade na Corporação YZ.

Tabela 12 - Resultado do exame psicológico dos ex-policiais militares admitidos entre 1994 e 2002 e que cometeram suicídio no mesmo período

\begin{tabular}{lc}
\hline Resultado do exame psicológico & Freqüência \\
\hline Indicado & 6 \\
Indicado com restrição & 10 \\
Contra-indicado & 7 \\
Eliminado & 1 \\
Não apurado & 1 \\
Total & 25 \\
\hline
\end{tabular}

Fonte: Diretoria de Recursos Humanos e Estado Maior.

Comparando-se o número de indicados (6) com o número de contra-indicados e indicados com restrição (17), nota-se que a proporção desses últimos é significativamente maior, o que vem comprovar a primeira hipótese secundária da pesquisa, a qual sustenta que vários policiais militares que cometeram suicídio foram contra-indicados ou indicados com restrição no exame psicológico.

Procedeu-se a um levantamento do tempo de serviço das vítimas de suicídio, constatando-se que $92 \%$ delas tinham menos de 6 anos de serviço; $84 \%$ não chegaram a completar 5 anos na Corporação YZ e 60\% não completaram 3 anos de serviço.

\section{Conclusões}

Embora há quarenta anos a Corporação YZ venha utilizando o exame psicológico nos processos seletivos, os resultados desse procedimento têm sido pouco avaliados tanto no âmbito da instituição quanto fora dela. Neste momento, torna-se necessário repensar o papel da avaliação psicológica no processo seletivo dessa organização e esta pesquisa pretendeu fazê-lo a partir dos resultados da negação do valor deste procedimento, pela admissão de candidatos considerados contra-indicados ou indicados com restrição.

A ênfase desta pesquisa, conforme o tema proposto, foi a avaliação dos policiais militares contraindicados no exame psicológico; para se ter um diagnóstico confiável e abrangente, foi necessário estabelecer comparações com os outros grupos indicados e indicados com restrição - a fim de se permitir uma análise crítica da situação.

O maior índice de admissão de servidores contra-indicados no exame psicológico ocorreu nos anos de 1994 e 1995, reduzindo-se nos anos seguintes e aumentando, novamente, no ano de 2002. Neste último ano, o ingresso de contra-indicados se deu exclusivamente por determinação judicial e, como a coleta de dados para esta pesquisa ocorreu em 2003, parece-nos oportuno avaliar, numa próxima pesquisa, os eventos ocorridos a partir da admissão desses policiais.

Os resultados da pesquisa nos permitem concluir que a hipótese principal foi comprovada, uma vez que, do contingente de policiais militares demitidos, bem como dos que cometeram crimes mas não foram demitidos e entre os que cometeram suicídio houve uma expressiva predominância de contra-indicados no exame psicológico.

Esses dados nos levam a sugerir que a predisposição para o cometimento desses desvios de comportamento pode ser identificada pelos testes psicológicos, aplicados por ocasião do processo seletivo. Ocorrem, também, casos em que mesmo não tendo resultados da avaliação psicológica que indiquem restrições por ocasião do processo seletivo, os policiais militares venham a apresentá-los ao longo de sua carreira. De acordo com a literatura, tais casos podem ser explicados por alterações de personalidade ou de adaptação, determinadas por múltiplos fatores, como as causas biológicas ou sociais, ou, ainda, por imposições de normas, regulamentos, valores, situação socioeconômica, padrões de convivência estabelecidos pela sociedade ou pela organização na qual o indivíduo trabalha e, também, pelas pressões impostas pelas condições de trabalho. Neste sentido, consideramos que os casos de desvios de comportamento cometidos por policiais militares admitidos sem restrições com base no exame psicológico realizado por ocasião do processo seletivo devem constituir objeto de outras pesquisas.

Psico-USF, v. 10, n. 2, p. 149-160, jul./ dez. 2005 
Uma limitação desta pesquisa é que tanto em relação às transgressões disciplinares como aos crimes $\mathrm{e}$ aos casos de suicídio, a análise foi baseada apenas na quantidade de registros e no resultado dos testes psicológicos. Seria necessário avaliar também os fatores que levaram à contra-indicação dos indivíduos ou à indicação com restrição, procedendo-se a uma análise comparativa entre os resultados dos testes e outros fatos que motivaram o comportamento desviante. Este estudo poderia constituir também sugestão para outra pesquisa.

Resta-nos, pois, sugerir que novas pesquisas sejam feitas com o objetivo de trazer novas informações sobre essas questões, oferecendo, deste modo, subsídios para a melhoria do desempenho dos policiais militares em todo o país.

Acredita-se que os resultados desta pesquisa possam oferecer ao Comando da Corporação YZ argumentos para discutir com o Poder Judiciário a admissão, em virtude de mandados de segurança, de candidatos contra-indicados com base na avaliação psicológica.

Sugerimos, pois, que seja encaminhada ao Tribunal de Justiça de Minas Gerais e ao Ministério Público Estadual uma exposição de motivos baseada neste trabalho e em outras fontes, para melhor subsidiar o entendimento de seus integrantes na apreciação de ações impetradas por candidatos eliminados e/ou contra-indicados em exame psicológico.

Tomando por base as conclusões obtidas nesta pesquisa, pode-se afirmar que admitir um indivíduo contra-indicado no exame psicológico para ser um policial militar, investindo-o de autoridade e poder, com a missão de proteger a sociedade, de portar e usar uma arma, de decidir sobre a vida e a morte, de agir em cenários de conflito e em situações de tensão é uma decisão temerária, pois se está colocando em risco não só o cidadão, que deve ser bem atendido e protegido por esse policial, como o próprio policial, que pode se tornar também uma vítima da sua condição psicológica.

A nossa conclusão é que se deve repensar os custos da admissão numa corporação policial militar de candidatos contra-indicados no exame psicológico, já que os transtornos apresentados por estes indivíduos ao longo da carreira - principalmente os desvios de comportamento - associados aos custos sociais, aos prejuízos morais e ao desgaste à imagem da instituição, não superam os investimentos do Estado na formação desses servidores.

Os dados desta pesquisa sugerem, ainda, que a aplicabilidade da psicologia é importante não apenas no processo seletivo, mas durante todo o tempo em que o policial militar estiver na ativa, em vista das pressões a que este profissional está sujeito no seu cotidiano de trabalho.

Psico-USF, v. 10, n. 2, p. 149-160, jul./ dez. 2005

\section{Agradecimentos}

À Academia de Policia Militar de Minas Gerais, à Escola de Governo da Fundação João Pinheiro e ao comando da PMMG.

\section{Referências}

Almeida, N. D. V. \& Almeida, L. F. (2003). Uso de técnicas e instrumentos psicológicos: reflexões pertinentes. ABRAMET - Associação Brasileira de Medicina de Tráfego, 42 (XXI).

Alves-Mazzotti, A. J. \& Gewandsznajder, F. (1999). O método nas ciências naturais e sociais: pesquisa quantitativa e qualitativa. São Paulo, SP: Pioneira Thomson.

Anastasi, A. \& Urbina, S. (2000). Testagem psicológica. 7a ed. Porto Alegre: Artmed.

Balestreri, R. B. (2002). Direitos humanos: coisa de polícia. 2a ed. Passo Fundo, RS: CAPEC; Bethier.

Freitas, O. A. (1995). Conduta de policiais militares que prejudicam a imagem da instituição: gênese e antecedentes (Dissertação de Mestrado). Minas Gerais: Academia da Polícia Militar do Estado de Minas Gerais.

Lakatos, E. M. \& Marconi, M. A. (1992). Fundamentos da metodologia científica. São Paulo, SP: Atlas.

Magalhães, C. A. T. (1996). Crime, sociologia e políticas públicas (Dissertação de Mestrado). Minas Gerais: Programa de Estudos de Segurança Pública, Universidade Federal de Minas Gerais.

Merton, R. K. (1968). Sociologia: teoria e estrutura. São Paulo: Mestre Jou.

Nicolau, A. A. (1993). Desvio de conduta de militares: fatores e reflexos na Policia Militar (Dissertação de Mestrado). Belo Horizonte, MG: Academia da Polícia Militar do Estado de Minas Gerais.

Nogueira, G. H. \& Moreira, A. L. (1997). Atos de extermínio entre policiais militares: algumas considerações. Revista de Psicologia: Saúde Mental e Segurança Pública, Belo Horizonte: PMMG, 1(1), p. 26-36.

Oleto, R. R. (1999). Estatística instrumental. Belo Horizonte, MG: Fundação João Pinheiro.

Pasquali, L. (2003). Avaliação psicológica: bases científicas e procedimentos. Anais do Congresso Sobre Avaliação Psicológica no Contexto da Seleção de Policiais. Brasilia: Academia Nacional de Polícia, p. 2.

Patrocinio, M. C. C. (1997). Desvio de conduta. Revista de Psicologia: Saúde Mental e Segurança Pública, Belo Horizonte: PMMG, 1(1), p. 68-69. 
Rezende, M. A. \& Cavazza, B. I. S. (1999). O policial militar e a violência: de agente a vítima. Revista de Psicologia: Saúde Mental e Segurança Pública, Belo Horizonte: PMMG, 1(2), p. 50-56.

Sampaio, J. R. (1998). Testes psicológicos nos processos de seleção de pessoal. Em Íris Barbosa Goulart \& Jáder dos Reis Sampaio (Org.). Psicologia do trabalho e gestão de recursos humanos: estudos contemporâneos. (pp. 149-167). São Paulo: Casa do Psicólogo.
Vergara, S. C. (2003). Projetos e relatórios de pesquisa em administração. São Paulo: Atlas.

Williams, M. R. (1972). Relações bumanas. São Paulo: Atlas.

Recebido em setembro de 2004

Reformulado em abril de 2005

Aprovado em julbo de 2005

Sobre os autores:

Divino Pereira de Brito é especialista em Segurança Pública e tenente-coronel da Polícia Militar de Minas Gerais.

Iris B. Goulart é doutora em Psicologia pela PUC-SP e professora do Departamento de Psicologia da UFMG. 